
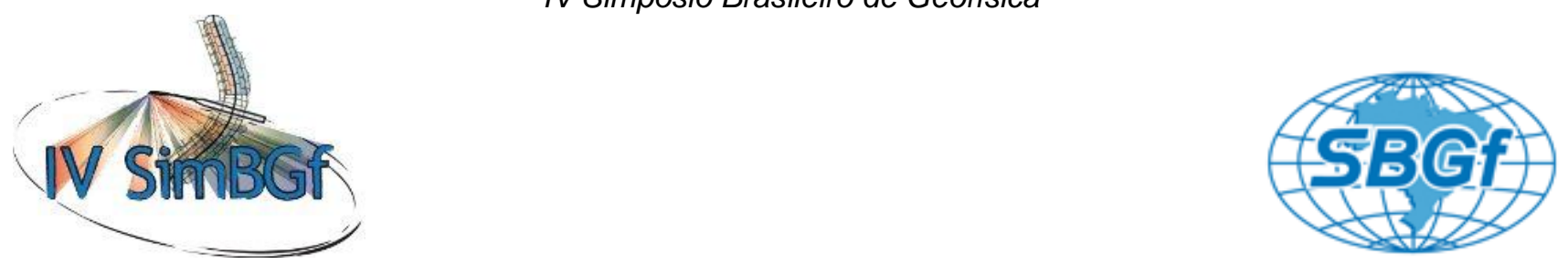

\title{
A workflow to constraining uncertainty in static reservoir modeling: a case study from Namorado Field, Brazil
}

Juliana Finoto Bueno, Alexandre Campane Vidal and Ancilla Maria Almeida de Carvalho*, Institute of Geosciences, University of Campinas

Copyright 2010, SBGf - Sociedade Brasileira de Geofísica

Este texto foi preparado para a apresentação no IV Simpósio Brasileiro de Geofísica, Brasília, 14 a 17 de novembro de 2010. Seu conteúdo foi revisado pelo Comitê Técnico do IV SimBGf, mas não necessariamente representa a opinião da SBGf ou de seus associados. É proibida a reprodução total ou parcial deste material para propósitos comerciais sem prévia autorização da SBGf.

\begin{abstract}
This work describes the reservoir-modeling case of Namorado, an oil field located in offshore Brazil. A geological uncertainty study was initiated to identify and quantify the input parameter of greatest impact in the reservoir model. In order to rank reservoir uncertainties, a series of static models were built and a method to quantify the uncertainty associated with geological parameters was tested. For construct the static reservoir model, the low, base and high-case of each uncertainty parameter were defined and used, and all combinations of these parameters were tested. The highest parameters contributors to uncertainty range in Stock Tank Oil Initially In Place (STOIIP) were identified and incorporated into workflow.
\end{abstract}

\section{Introduction}

The use of 3D geological models in many areas of geoscience has become largely widespread as a result of improvements in computer processing power. By applying a model successfully, it has to represent the 'real' situation as accurately as possible. In the geological context, the 'real' situation is often unknown and the model represents an interpretation, based on limiting assumptions, of what is likely to occur between data points (Lelliot et al. 2009). Each input data used to build the 3D static reservoir model carries an uncertainty that cannot be expressed in a single deterministic realization.

Zabalza-Mezghani et al. (2004) classified sources of uncertainty in reservoir engineering as anywhere within the reservoir modeling workflow, such uncertainties associated with: static model, upscaling, fluid flow modeling, production data integration, production scheme development and economic evaluation. These authors classified the different uncertainty behavior as uncertainties: deterministic, discrete and stochastic. The different parameters were classified as uncontrollable and controllable. Mann (1993) suggested four main categories of uncertainty in geology: (1) variability: the inherent natural variability that exists in geological objects; (2) measurement: uncertainty caused by imperfections in the measurement procedure; (3) sampling: uncertainty that arises from the process of making a measurement at a specific spatial location; (4) modeling: uncertainty associated with processing of the data to create the model.

The Namorado Field was the first giant offshore Brazil oil field and it has been productive since 1979 (Winter et al. 2007). It has estimated oil in place volume of 669 million bbl of oil or $106 \times 10^{6} \mathrm{~m}^{3}$ (Guardado et al. 1989). Although the volumetric estimate of the field to be known the uncertainty associate with the static reservoir model is not well established.

The purposes of this study are to focus on identify and quantify uncertainties associated with geological parameters used to modeling the Namorado Field static reservoir and how it affects the volumetric estimation.

\section{Field description}

\section{Geological setting}

The Namorado Field is located in the central part of Campos Basin in Brazil's continental platform. Campos Basin is a passive continental margin type basin formed during the breakup of the Gondwana supercontinent as a consequence of South American and African separation (Guardado et al. 1989). The Campos Basin is composed by several hydrocarbon production fields with OligoMiocene ages and the sediment starvation occurred in the basin from the Cenomanian to the Maestrichtian as a consequence of tectonic subsidence, eustatic sea-level rise and a relatively low influx of terrigenous sediments (Guardado et al. 1989). It contains reserves higher than 250 million bbl (Mendonça et al. 2004) responsible for more than $90 \%$ of Brazil's current reserves (Winter et al. 2007).

The Namorado Field was discovered by Petrobrás in 1975 and became the first giant offshore Brazilian oil field. The mainly reservoir is the Cenomanian turbidite Namorado sandstone that occurs in depths between 2900 and $-3400 m$ (Meneses \& Adams 1990). The Namorado sandstone is composed by turbidite sands deposited during the Cenomanian/Turonian and intercalated with shale and carbonates. The Namorado field is a faulted structure shared into five blocks by normal faults. The mainly block hydrocarbon producer is a central one in the field. Hydrocarbon accumulation is controlled by turbidite sandstone pinchout and by the structural features. The reservoir seals are marbles and shales of the hemipelagic sequence (Guardado et al. 
1989). The turbidite sandstones reach thickness at about $115 \mathrm{~m}$ and are usually massive, medium-grained, arkosics and locally conglomeratics (Guardado et al. 1989, Meneses e Adams 1990, Barboza 2005). The sandstones has porosity between 20 to $30 \%$ and permeability higher than 1 darcy (Guardado et al. 1989, Meneses \& Adams 1990).

\section{Database}

The Namorado Field is covered by a 3D seismic survey that was used to derive structural and sedimentological information to reservoir evaluation. A total of 55 wells drilled and logged between 1975 and 1986 were used in this study. The well logs presented in the dataset are: density (RHOB), gamma-ray (GR), resistivity (ILD), neutron porosity (NPHI) and sonic (DT). Eight wells were cored and qualitative petrographic description is available. The dataset is currently available by the Brazilian National Agency of Petroleum (ANP).

\section{Workflow}

This study is conducted in a geostatistical framework, in the Roxar Irap-RMS, using stochastic modeling techniques to build the geological model based on geometry, geology and petrophysical properties of the reservoir. The workflow set up is a scenario-based workflow where high and low cases around the base case are defined to each of the parameters under investigation. For each parameter the high and low cases were relative to the mean value of the variable distribution, the multiple stochastic realizations were run.

This study is conducted in a geostatistical framework, in the Roxar Irap-RMS, using stochastic modeling techniques to build the geological model based on geometry, geology and petrophysical properties of the reservoir. The workflow set up is a scenario-based workflow where high and low cases around the base case are defined to each of the parameters under investigation. For each parameter the high and low cases were relative to the mean value of the variable distribution, the multiple stochastic realizations were ran.

In Irap-RMS, the workflow consists of a series of IPL (Internal Programming Language) scripts that execute a routine of modeling jobs whereby the parameter under investigation is varied whilst all other parameters are held to the high, base and low-case model. This kind of investigation is known as a 'three levels full factorial' experimental set-up. Each IPL workflow job involves the building of a model, from facies to petrophysical modeling and finally to volume calculations to give the response variable for that particular scenario (Keogh et al. 2008).

The workflow comprises the following steps: (1) construction of the structural model; (2) construction of the geological model; (3) populate the geological model with petrophysical parameters; (4) uncertainty analysis. The workflow used to model The Namorado Field consisted of three phases, each progressively more complex. An initial phase comprises steps 1,2 and 3 to defined high, base and low-case of static model. The second iteration of static models was built to address the uncertainty in used parameters to construction the static model. In the third iteration highest ranked contributors to uncertainty were used to constraint the oil field volume.

\section{Stage 1: Construction of the structural model}

The data consist of a set of depth markers measured along the wells, which give the true vertical depth at the intersections of the well with the layer surfaces, and several seismic horizons picked in time units. Three depositional sequences were found in 3D seismic, sequences 3,2 and 1; top and bottom of reservoir was defined in OpenDtect software. After conversion of the seismic horizons picks into depth units, the top was used as reference surface for the reservoir organization; all the estimated surfaces are more or less parallel to this reference surface. The major eight faults found in reservoir area were used to building the structural model.

The densities of the 3D seismic and well data are high enough to minimize the uncertainties associated with the construction of the structural model. For these reason we consider the model created in this step as input for the high, base and low-scenarios.

\section{Stage 2: Construction of the geological model}

The facies were defined with the utilization of k-nearest neighbors algorithm which is a method for classifying objects based on closest training examples in the feature space. The k-NN is a type of instance-based learning, or lazy learning where the function is only approximated locally and all computation is deferred until classification (Hechenbichler \& Schliep, 2004). Cored wells were used as training examples for k-NN classification and facies were classified in reservoir, possible-reservoir and notreservoir.

In order to capture reservoir heterogeneities, grid cell resolution was defined as $50 \times 50 \times 1 \mathrm{~m}$. The facies log defined in wells, with k-NN algorithm, was scaled to this grid resolution without loss of heterogeneity.

The facies model was built using Sequential Indicator Simulation (SIS) with vertical trend. Vertical facies proportions were identified to each reservoir layer from block wells facies log. SIS is an algorithm used to generate a discrete $3 \mathrm{D}$ facies parameter for the current realization. Each cell in the parameter is assigned a facies code defining the facies type (reservoir, possiblereservoir and non-reservoir) present in that cell, based on probabilities calculated from well data and user-defined input. Although SIS does not result in geological bodies, elongation direction can be imposed through use of the variogram model. For all reservoir layers, the percentage of each facies within the low, base and high-case honored the field mean percentage of that facies preserved in wells.

Stage 3: Populate the geological model with petrophysical parameters

Calculated porosity and water saturation curves for wells were used to property modeling of reservoir- and possible-reservoir facies at the Namorado field. Porosity 
and water saturation data was scaled up to grid resolution without loss of heterogeneity and checked for trends related to depth. Variograms in all directions were developed for each facies from blocked well data. Sequential Gaussian Simulation (SGS) was then used to populate grid cells. SGS is a kriging-based method in which unsampled locations are sequentially visited in a random order until all unsampled points are visited (Kelkar and Perez, 2002). Porosity and water saturation are then simulated, reproducing per-facies distribution as derived from the blocked well data. Interval average porosity cut-off $>20 \%$ was used to calculate net-to-gross (NTG) to each interval. NTG were then calculated for the geological models in each of the three reservoir layers from blocked well data. Based on water saturation two oilwater-contacts were defined according to main fault that divide the Namorado Field in two blocks. Oil-water contacts were defined in $-3100 \mathrm{~m}$ to the high-block and 3145 to the low-block.

\section{Stage 4: Uncertainty analysis}

After the stages described above, 100 facies and petrophysical parameters realizations were generated by varying seed number alone. In this first iteration parameters were ranked by STOIIP and P90, P50 and P10 cases picked as low, base and high-case for porosity, water saturation and net-to-gross models.

In the second iteration were addressing uncertainties associated with parameters used in iteration 1. A PVT study had reported a base case Bo factor around 1\% uncertainty and for this reason Bo factor was not included in uncertainty analysis. In this step the parameters that are actually influent on the production response were identified. Low, base and high-case models were used to addressing uncertainties associate do 3D porosity, water saturation and net-to-gross parameters. To addressing uncertainties associates to variographic parameters like range, azimuth and direction, normal distribution option was used. Using this option, for each project realization, the value of the uncertainty will be sampled for the defined normal (Gaussian) distribution. For this option, a mean and standard deviation must be specified. This type of distribution was used in this stage because this is less time consuming than low-, base- and high-cases.

For the second iteration 243 realizations of the workflow were ran. The algorithm three levels full factorial was used in this iteration. Using this algorithm, all combinations of high, base and low values for each sensitivity was tested. In addition, the combination with all sensitivities at base value was tested. Latin Hypercube was used as sampling method. This method prescribes a subdivision of the distribution into $\mathrm{N}$ equiprobable intervals. Then, a number is randomly selected from each of the $\mathrm{N}$ intervals in order to achieve a better representation of the underlying distribution. Tornado style plot was used to ranking each parameter in terms of their contribution to total uncertainty range in STOIIP (Fig. 1) and the highest ranked contributors to uncertainty were: (1) oil-water contact for high-block in the field, (2) oil-water contact for low-block in the field, (3) range of variogram used for porosity simulation in parallel direction and (4) range of variogram used for water saturation simulation in parallel direction. Probably the oil-water contact in the high and low-block is not flat in the field and as a single value for this contact for each one block was adopted this caused a large impact in the uncertainty analysis. The variogram model describes the spatial correlation between the parameter in interest as a function of their separation distance. The possiblereservoir facies and their petrophysical properties can have an erratic distribution along the wells in the Namorado field causing its impact in uncertainty sensitive analysis.



Figure 1- Tornado style plot ranking each parameter in terms of their contribution to total uncertainty range in STOIIP with most significant at the top to least significant at the bottom.

In the third iteration the parameters ranked in the iteration 2 were used for addressing uncertainty in the high, base and low-case models. This option is typically used in sensitivity studies, where the aim is to investigate the effect of the different uncertainties/sensitivities relative to each other, or alternatively, the effect on the total uncertainty. In this iteration the three levels full factorial algorithm was used and 81 realizations of this workflow were ran. The STOIIP obtained after the third iteration was: $91.88 \times 10^{6} \mathrm{~m}^{3}$ for P90, $97.39 \times 10^{6} \mathrm{~m}^{3}$ for P50 and $111.56 \times 10^{6} \mathrm{~m}^{3}$ for P10 scenarios (Fig. 2).

\section{Conclusions}

The workflow used in this study successfully integrated all geological uncertainty scenarios, and produced significant results. A modeling workflow has been established to handle both multiple scenarios and multiple realizations of a given scenario. 
The combination of depositional facies cases, porosity and water saturation cases, net-to-gross ratio and oilwater contact uncertainties resulted in 243 estimates of hydrocarbon volume and the rank of the impact of these parameters in volume estimation. The 'top 4' highest contributors to uncertainty range in STOIIP as identified and its uncertainties were used to build the low, base and high-case scenarios to the Namorado Field. After 81 realizations of all combinations of each low, base and high 'top 4' parameter the hydrocarbon volume for Namorado Field was established varying from 97.39 to $111.56 \times 10^{6} \mathrm{~m}^{3}$ which are comparable to a $106 \times 10^{6} \mathrm{~m}^{3}$ presented by Guardado et al. (1989).

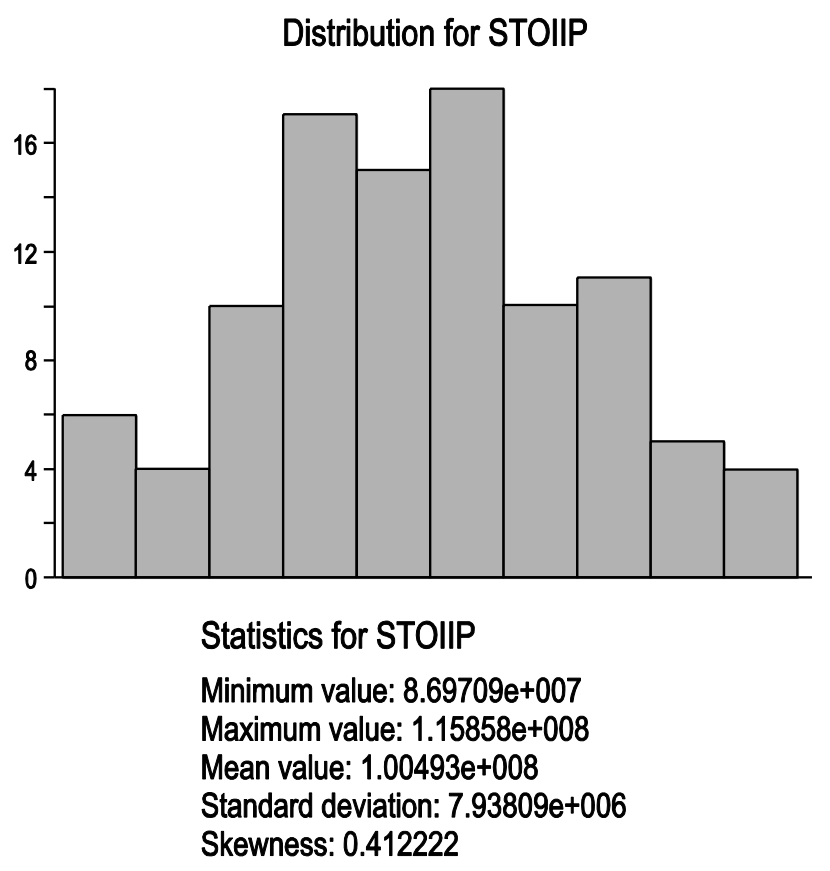

P90: 9.18873 e+007 (proj. real 4)

P80: $9.38684 \mathrm{e}+007$ (proj. real 50)

P50: 9.739 e+007 (proj. real 37)

P20: $1.10104 \mathrm{e}+008$ (proj. real 72)

P10: $1.1156 \mathrm{e}+008$ (proj. real 54 )

Figure 2- Histogram showing the total range in STOIIP.

\section{Acknowledgements}

The authors acknowledge the financial support of Petrobrás and Roxar is thanked for the use of Irap-RMS software. Moacir Cornetti and Sérgio Sacani Sancevero are greatly acknowledged for useful suggestions.

\section{References}

Guardado, L. R., Gamboa, L. A. P. \& Lucchesi, C. F. 1989. Petroleum geology of the Campos basin, Brazil: a model for a producing atlantic-type basin. In: Edwards, J. D. \& Santogrossi, P. A. (Eds.) Divergent/passive margin basins. AAPG Memoir, 48: 3-80.

Hechenbichler, K. \& Schliep, K. 2004. Weighted kNearest-Neighbor techniques and ordinal classification: Collaborative Research Center 386, discussion paper 399, University of Munich, $16 \mathrm{p}$.

Kelkar, M. \& Perez, G. 2002. Applied Geostatistics for Reservoir Characterization. Society of Petroleum Engineers, $264 \mathrm{pp}$.

Keogh, K. J., Berg, F. K. \& Petek, G. 2008. A method for quantifying geological uncertainties in assessing remaining oil targets: a case study from Glitne Field, North Sea. In: Robinson, A., Griffiths, P., Price, S., Hegre, J. \& Muggeridge, A. (Eds.). The future of Geological Modelling in Hydrocarbon Development. The Geological Society, London, Special Publication, 309: 193-203.

Lelliott, M. R., Cave, M. R. \& Wealthall, G. P. 2008. A structured approach to the measurement of uncertainty in 3D geological models. Quarterly Journal of Engineering Geology and Hydrogeology, 42: 95-105.

Mann, C. J., 1993. Uncertainty in geology. In: Davis, J. C. \& Herzfeld, U. C. (Eds.) Computers in Geology - 25 Years of Progress. Oxford University Press, Oxford, pp. 241-254.

Meneses, S. X., \& Adams, T. 1990 Ocorrência de resistividades anômalas no Campo de Namorado, Bacia de Campos. Boletim de Geociências da Petrobras, 4: 183-188.

Winter, W. R., Jahnert, R. J. \& França, A. B. 2007. Bacia de Campos. Boletim de Geociências da Petrobrás, 15: 511-529.

Zebalza-Mezghani, I., Manceau, E., Feraille, M. \& Jourdan, A. 2004. Uncertainty management: From geological scenarios to production scheme optimization. Journal of Petroleum Science and Engineering, 44: 11-25. 